\title{
Effect of Handoff Training on Resident Communication Quality: An Observational Study
}

\author{
Joanna Abraham \\ University of Illinois at Chicago \\ abrahamj@uic.edu
}

\author{
Christopher Bogan \\ University of Illinois at Chicago \\ cwbogan@gmail.com
}

\author{
Thomas G. Kannampallil \\ University of Illinois at Chicago \\ tgk2@uic.edu
}

\author{
Charlotte E. Ward \\ Northwestern University \\ charlotte.ward@northwestern.edu
}

\author{
Abbas Hyderi \\ University of Illinois at Chicago \\ ahyder2@uic.edu
}

\begin{abstract}
We evaluated the effect of handoff training conducted during resident orientation on communication quality using a non-randomized between-subjects study, where the training group received structured, in-person handoff training, and the control group received no training. Handoff conversations for both groups were audio-recorded. Communication quality was measured as the frequency of communication breakdowns. We found that training group had fewer breakdowns; however, after adjusting for patient acuity and patient days in the unit, communication quality between the two groups were similar $(O R=0.3,95 \% C I=0.08-1.07$, $p=0.06)$. However, there were significant differences in the clinical content exchanged during communication: compared to the control group, residents in the training group discussed significantly more clinical content related to identifying information, past medical history and contextual information; and less clinical content related to active problems and assessment of active problems. We discuss the implications of such handoff training program during resident orientations.
\end{abstract}

\section{Introduction}

Reduction in resident duty hours has changed clinical practice in several ways [1, 2]. Handoffs are a prominent area where duty hour restrictions have had an impact, with increased frequency of care transitions that involve the transfer of information, responsibility, and control between residents [3, 4].

Resident handoffs are prone to incomplete, inaccurate, or misinterpreted information, leading to communication errors, with a potential impact on patient safety and quality outcomes [5-8]. Concerted efforts by World Health Organization, Institute of Medicine, and The Joint Commission to ensure handoff safety and quality have focused on standardizing the content of handoff communication using handoff tools, proformas, and mnemonics [9, 10]. However, reports on compliance to such handoff standardization efforts have been mixed [11].

Besides handoff tool-based standardization, recent initiatives have focused on incorporating training as part of the medical education and residency curricula [12]. Proposals for formal handoff training [13] during graduate medical education with emphasis on core competencies have been formulated [14]. However, there is limited consensus on what such training methods should entail, or how it can be incorporated into a medical school or residency curricula [14-20].

Given the lack of clarity in the available guidelines and tailored protocols for handoff training, residents are often unaware of the potential challenges of handoffs and handoff strategies for effective communication [21]. As a result, recent research has noted that trainees are dissatisfied with current handoff practices and are under-prepared for performing handoffs [15]. A recent national survey of Clerkship Directors of Internal Medicine found that only a minority of programs (15\%) provided handoff training during Internal Medicine core clerkships [22]. Previous national surveys have reported that only $8 \%$ of medical schools teach handoffs in a formal didactic session [23].

In response to these challenges, a number of training programs have been developed and implemented, especially at academic institutions [11]. These programs include formal face-to-face handoff 
didactics [24], formal face-to-face handoff didactics with role play exercises [25], web- or video-based educational modules [26-29], and simulated training sessions [30, 31]. In a systematic review, Gordon and Findley [15] reported that there was significant variability among these training interventions, and argued that the evidence regarding the effectiveness of these training programs was limited. Additionally, they found that there was limited summative evaluation of the impact of handoff training on the quality and effectiveness of handoff communication and outcomes [15].

Despite these initiatives for teaching handoffspecific skills for residents [14-16], what currently exists in most hospitals are cursory training sessions (or no training)—often conducted during general orientation sessions, with limited follow-up or formalized tracking of handoff competencies. The reason for such minimal training is driven by a combination of factors: low cost, lack of time, and limited effort required for such training [32]; limited consensus on the elements of a focused handoff training program [33-35]; and most importantly, lack of a general set of principles or gold standard for defining a successful handoff [36].

Although resident training sessions vary in content and format, most orientations involve a general overview of commonly-used handoff practices and the specific handoff tools and informal communication mechanisms adopted at that institution. In spite of such training being common across academic medical centers, we know very little about the effectiveness or impact of such training on the quality of handoff communication. To the best of our knowledge, there has been no research published on the systematic evaluation of the effect of such handoff training on handoff outcomes. In this paper, we report on the results from an observational study evaluating the effect of a routine handoff training on communication quality during handoffs.

\section{Method}

\subsection{Study Setting}

This study was conducted at the General Medicine (GM) unit at a Midwestern academic hospital. For managing patient volume across the GM unit, it is divided into four medicine services (named A, B, C and D), with similar clinical workflows and responsibilities. Each medicine service has a capacity to admit up to 25 patients. An attending physician, four residents (1 PGY3, 1 PGY2, and 2 PGY1), nurses, and a clinical pharmacist manage each service. The nurse-to-patient ratio is approximately 6:1; all nurses reported to a charge nurse.

\subsection{Resident Handoffs}

Residents belonging to all four medicine services followed the same shift schedule: a day shift (7AM to 5PM) and a night shift (5PM to 7AM). Resident handoffs were face-to-face, and were often conducted in a conference room outside the unit. An outgoing resident from each service came to the conference room at consecutive time slots to handoff their patient cases to an incoming resident. Although resident shifts switched twice daily, formal handoffs occurred only at 5PM.

In preparation for handoff, outgoing residents gathered patient information using an electronic document template structured according to the problem-based SOAP (Subjective Objective Assessment and Plan) format. This document included fields for patient identifying information, past medical history, active problems, assessment of active problems, medications and treatments, to-do tasks, and care goals (See Figure 1). The handoff document was maintained on an encrypted shared drive outside of the institution's EHR system. During handoffs, an outgoing resident used the completed handoff document as a cognitive aid for verbal communication.

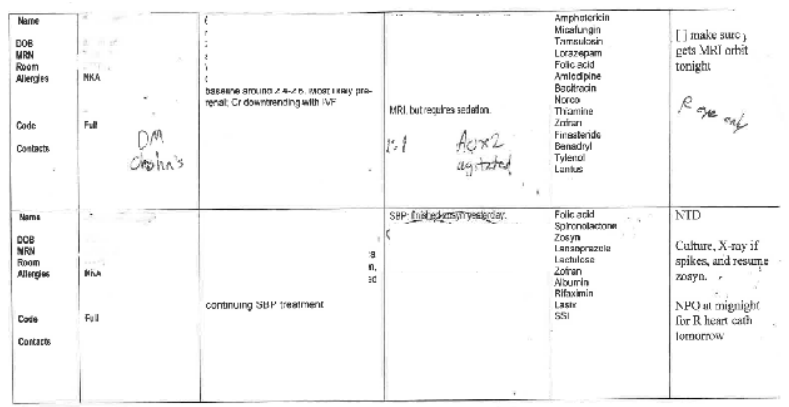

Figure 1. Handoff document that is used by residents in the GM unit. Each row depicts the information recorded for a single patient.

\subsection{Study Design}

We used a non-randomized, between-subjects design to investigate the effect of handoff training on communication quality. Residents who were assigned to services A and C during the study period were provided face-to-face handoff training (training condition). In contrast, residents assigned to services $\mathrm{B}$ and $\mathrm{D}$ received no formal or informal handoff training (control condition). Historically, residency program directors and coordinators in the GM units did not provide any training for residents on handoffs. The institutional review board of the University approved this study, and written consents were obtained from all participants. 


\subsection{Handoff Training}

The development of our training program was informed by standard handoff training programs provided at academic medical centers and also by informal discussions with medical educators including chief residents and residency program directors [37]. The training was delivered as a 30minute didactic session, followed by an interactive Q\&A session. The training materials for the didactic session were developed based on an extensive review of the handoff communication research, and based on our prior experience with sessions on soft skills training for medical students and clinical professionals (during 2014-2016).

The didactic session focused on highlighting key topics related to handoffs, strategies for successful handoffs, the clinical elements to be covered during handoffs, and the different roles (i.e., incoming and outgoing) and information expectations during handoffs. We presented short case studies to highlight the potential for sentinel events caused by communication failures. In addition, residents were provided detailed information on the history and functionalities of the electronic handoff document used in the GM unit, how to access the electronic handoff document, how to fill in the details, and how to use the electronic handoff document to manage effective handoff communication.

During the interactive session, trainers answered residents' questions regarding safe handoff practices and discussed strategies for conducting safe, effective, and efficient handoffs.

Handoff training was conducted during the mandatory GM unit orientation sessions for residents rotating in the four GM services, and was provided only to residents assigned to services $\mathrm{A}$ and $\mathrm{C}$.

\subsection{Data Collection}

The data collection involved audio recording of resident handoff communication followed by retrospective patient chart reviews. We audiorecorded the 5 PM formal handoff conversations between residents over a two-month period for 184 patients (ntraining=80, ncontrol=104). Participants included 8 resident physicians (2 PGY3, 2 PGY2, and 4 PGY1).

We conducted retrospective chart reviews for all patients using a standardized chart abstraction tool $[38,39]$. We extracted patient information related to the following: patient demographics, and their clinical characteristics [40, 41] including patient age, gender, patient-reported race, patient admission date and time, clinical diagnoses, home medications, number of days in the unit (prior to the recorded handoff), unexpected transfers to a higher-level of care (e.g., ICU transfer). In cases of questions and discrepancies during the chart abstraction process, the first and fourth authors met to discuss until a consensus was reached.

We considered two covariates based on prior research on handoffs: the acuity of the patient, and patient days in the unit. The acuity of the patient was determined based on a calculated Charlson score, as it is generally acknowledged that sicker patients have many clinical parameters to monitor and hence involve the transfer of more complex information $[42,43]$. Charlson score was calculated using a combination of the patient's clinical conditions, age and other related characteristics retrieved during chart review [44, 45]. Patient days in the unit was based on the determination whether the patient was a new admission to the unit or not, as there could be differences in clinical content based on the number of days the patient spent in the unit [46].

\subsection{Data Analysis}

2.6.1. Qualitative Conversational Analysis. The audio-recorded handoffs were de-identified to remove any patient identifying information, and then transcribed by a professional medical transcription agency.

Clinical Content Segmentation in Handoff Communication: Conversational analysis techniques were used to qualitatively code the transcripts [4, 5, 47-49]. Prior to coding, each handoff transcript was segmented into utterances. An utterance is a conversational unit that carries meaning. Examples include statements, commands, or single words. Utterances were further coded based on the speaker (i.e., outgoing vs. incoming resident). Two graduate student coders performed the segmentation task independently and the first author (JA) independently reviewed all segmented transcripts for accuracy. Any disagreements were resolved through discussion. An example of the segmentation of the verbal content is illustrated in Table 1.

\section{Table 1. Segmentation of verbal conversations into incoming and outgoing resident conversations.}

\begin{tabular}{|l|l|l|}
\hline Speaker & Description & $\begin{array}{l}\text { Example (from } \\
\text { data) }\end{array}$ \\
\hline $\begin{array}{l}\text { IN (Incoming } \\
\text { Resident) }\end{array}$ & $\begin{array}{l}\text { A meaningful } \\
\text { piece of } \\
\text { information from } \\
\text { the incoming } \\
\text { resident }\end{array}$ & $\begin{array}{l}\text { IN: “Platelets are } \\
\text { fine?" }\end{array}$ \\
\hline OUT & A meaningful & OUT: "Yeah. \\
\hline
\end{tabular}




\begin{tabular}{|l|l|l|}
\hline $\begin{array}{l}\text { (Outgoing } \\
\text { Resident) }\end{array}$ & $\begin{array}{l}\text { piece of } \\
\text { information from } \\
\text { the outgoing } \\
\text { resident }\end{array}$ & $\begin{array}{l}\text { Platelets today } \\
\text { dropped from like } \\
150 \text { to like 125” }\end{array}$ \\
\hline
\end{tabular}

Clinical Content Coding in Handoff Communication: After segmentation, utterances were coded based on their clinical meaning. The clinical content coding used in this study was informed by a handoff communication content framework used in prior research [5, 50]. The first author has significant training experience and expertise in communication analysis using the handoff communication content framework [4, 5, 47]. Clinical content categories, their description, and examples from the data are provided in Table 2.

\section{Table 2. Clinical content categories exchanged during resident handoff communication (adapted from Abraham et al. [4], with permission).}

\begin{tabular}{|c|c|c|}
\hline $\begin{array}{l}\text { Content } \\
\text { Categories }\end{array}$ & Description & Example \\
\hline $\begin{array}{l}\text { Identifying } \\
\text { information }\end{array}$ & $\begin{array}{l}\text { Patient socio- } \\
\text { demographics, and } \\
\text { contact information }\end{array}$ & $\begin{array}{l}\text { "35 year old } \\
\text { male"”" }\end{array}$ \\
\hline Code Status & Code status of patient & $\begin{array}{l}\text { "He is now } \\
\text { DNR/DNI" }\end{array}$ \\
\hline Allergies & Patient drug allergies & $\begin{array}{l}\text { "Patient is } \\
\text { allergic to } \\
\text { penicillin" }\end{array}$ \\
\hline $\begin{array}{l}\text { Admission } \\
\text { and } \\
\text { Disposition }\end{array}$ & $\begin{array}{l}\text { Admission and } \\
\text { disposition information } \\
\text { (tasks, location and } \\
\text { time) related to } \\
\text { discharge, or transfer }\end{array}$ & $\begin{array}{l}\text { “..looks like they } \\
\text { are transferring } \\
\text { him out } \\
\text { tomorrow” }\end{array}$ \\
\hline $\begin{array}{l}\text { Past Medical } \\
\text { History }\end{array}$ & $\begin{array}{l}\text { Any past clinical } \\
\text { diagnosis and surgeries, } \\
\text { procedures etc. }\end{array}$ & $\begin{array}{l}\text { "She has two } \\
\text { ostomies on her } \\
\text { abdomen from } \\
\text { past surgical } \\
\text { procedure"; } \\
\text { "She does have a } \\
\text { history of } \\
\text { compartment } \\
\text { syndrome" }\end{array}$ \\
\hline $\begin{array}{l}\text { Active } \\
\text { Problems }\end{array}$ & $\begin{array}{l}\text { All active diagnoses } \\
\text { and conditions being } \\
\text { treated during current } \\
\text { hospital encounter }\end{array}$ & $\begin{array}{l}\text { "She was found } \\
\text { to have a UTI"; } \\
\text { "And she started } \\
\text { complaining of } \\
\text { severe leg pain" }\end{array}$ \\
\hline $\begin{array}{l}\text { Assessment of } \\
\text { Active } \\
\text { Problems }\end{array}$ & $\begin{array}{l}\text { Current status of active } \\
\text { problems according to } \\
\text { care providers and } \\
\text { patient/care givers }\end{array}$ & $\begin{array}{l}\text { "There is (are) } \\
\text { no acute issues" }\end{array}$ \\
\hline $\begin{array}{l}\text { Anticipatory } \\
\text { Guidance }\end{array}$ & If/then statements & $\begin{array}{l}\text { "If the CK is } \\
\text { elevated go } \\
\text { ahead and }\end{array}$ \\
\hline
\end{tabular}

\begin{tabular}{|c|c|c|}
\hline & & $\begin{array}{l}\text { started low dose } \\
\text { maintenance IV } \\
\text { fluids” }\end{array}$ \\
\hline $\begin{array}{l}\text { Pending } \\
\text { Labs/Studies/ } \\
\text { Procedures }\end{array}$ & $\begin{array}{l}\text { All ongoing/pending } \\
\text { laboratory studies or } \\
\text { procedures }\end{array}$ & $\begin{array}{l}\text { "He is getting } \\
\text { MRI right now } \\
\text { of his legs" }\end{array}$ \\
\hline $\begin{array}{l}\text { Medications/ } \\
\text { Treatments }\end{array}$ & $\begin{array}{l}\text { Medications and } \\
\text { treatments and their } \\
\text { status (including } \\
\text { administration, patient's } \\
\text { response to } \\
\text { medications/treatments) }\end{array}$ & $\begin{array}{l}\text { "They } \\
\text { recommended } \\
12 \text { mg tonight”; } \\
\text { "He has been } \\
\text { getting LR } 200 \\
\text { cc per hour" }\end{array}$ \\
\hline Tasks/To do & $\begin{array}{l}\text { Incoming and Outgoing } \\
\text { clinician tasks to be } \\
\text { performed during shift }\end{array}$ & $\begin{array}{l}\text { "You can give } \\
\text { her [pain] dose } \\
\text { overnight" }\end{array}$ \\
\hline Family & $\begin{array}{l}\text { Any information } \\
\text { regarding patient } \\
\text { family }\end{array}$ & $\begin{array}{l}\text { "But the family } \\
\text { is there all } \\
\text { time"; "The } \\
\text { family always } \\
\text { stays there?" }\end{array}$ \\
\hline $\begin{array}{l}\text { Situated } \\
\text { Context }\end{array}$ & $\begin{array}{l}\text { Any non-clinical and } \\
\text { social information (that } \\
\text { cannot be coded in the } \\
\text { clinical categories } \\
\text { above) }\end{array}$ & $\begin{array}{l}\text { "Security will } \\
\text { escort him out. } \\
\text { So that's it, } \\
\text { okay." }\end{array}$ \\
\hline
\end{tabular}

The first author (JA) and a trained graduate research assistant independently coded all transcripts. The handoff content framework used in this study was relatively straightforward to apply as it followed a systematic problem-based format. However, given the clinical nature of the data, five transcripts were randomly selected and independently coded by a physician. The clinician coding was compared to the coding of the researchers. Comparisons of the coding between the physician and researcher showed high inter-rater reliability (Cohen's $\mathrm{K}=0.98, \quad 98.4 \%$ agreement). The agreement reached $100 \%$ after review and discussion.

Clinical Content Breakdowns in Handoff Communication: Studies on patient safety have demonstrated that handoffs are prone to communication breakdowns [48]. A communication breakdown during handoffs represents a failure in conveying a message by the outgoing resident to the incoming resident [5, 7, 47]. A communication breakdown can be caused by incomplete information and/or incorrect information provided by the outgoing resident.

We used breakdowns in communication to evaluate the quality of resident handoffs. Two coders categorized the breakdowns with 86\% agreement (Cohen's K=0.89). Disagreements were resolved through discussion and agreement reached $100 \%$.

2.6.2. Statistical Analysis. Handoff data were categorized dichotomously based on the control and training groups. Clinical content was operationalized 
as the proportion of utterances pertaining to a clinical content category divided by the total number of utterances during that handoff. For example, for the active problems category, the proportion was calculated by dividing the number of active problem utterances by the total number of utterances during that patient handoff. The primary outcome measure was dichotomized based on whether there was a communication breakdown or not.

The association between handoff training and breakdown in communication was analyzed using a logistic regression model. In a secondary analysis, the association between the handoff training and the nature of clinical content shared during handoffs (see Table 2) was assessed using a series of binomial regression models, one per clinical content category.

The analysis was also repeated by controlling for the covariates Charlson co-morbidity score, and patient days in the unit (new patient, existing patient). A statistical significance level of $p<0.05$ was used for all comparisons. All analyses were performed using SAS software version 9.4 (SAS Institute, Cary, North Carolina).

\section{Results}

A total of 80 handoffs were conducted by residents in the training group, and 104 handoffs were conducted by residents in the control group. Patients in the training group were older (mean age (SD): 59.3 (17.6) vs. 51 (16.6); p=0.001), more likely to have a Charlson score $\geq 2$ (68.8\% vs. 52.9\%; $\mathrm{p}=0.03)$.

Table 3. Descriptive summary statistics across the training and control groups.

\begin{tabular}{|c|c|c|c|}
\hline Variable & $\begin{array}{l}\text { Trainin } \\
\mathbf{g}(n=80)\end{array}$ & $\begin{array}{l}\text { Control } \\
(n=104)\end{array}$ & $\begin{array}{c}\text { p- } \\
\text { value } \\
*\end{array}$ \\
\hline Age, mean (SD), y & $\begin{array}{c}59.3 \\
(17.6) \\
\end{array}$ & $\begin{array}{c}51 \\
(16.6) \\
\end{array}$ & 0.001 \\
\hline Female & $\begin{array}{c}38 \\
(47.5)\end{array}$ & $\begin{array}{c}45 \\
(43.27)\end{array}$ & 0.57 \\
\hline \multicolumn{4}{|l|}{ Race } \\
\hline White & $\begin{array}{c}17 \\
(21.3) \\
\end{array}$ & $\begin{array}{c}15 \\
(14.4) \\
\end{array}$ & \multirow{3}{*}{0.46} \\
\hline Black/African American & $\begin{array}{c}44 \\
(55.0)\end{array}$ & $\begin{array}{c}69 \\
(66.4)\end{array}$ & \\
\hline Other & $2(2.5)$ & $2(1.9)$ & \\
\hline Hispanic & $\begin{array}{c}17 \\
(21.3)\end{array}$ & $\begin{array}{c}18 \\
(17.3)\end{array}$ & 0.5 \\
\hline $\begin{array}{l}\text { Patient days in the unit } \\
\text { (No. of days in unit }=0 \text { ) }\end{array}$ & $4(5.0)$ & $10(9.6)$ & 0.24 \\
\hline Charlson Score $>2$ & $\begin{array}{c}55 \\
(68.8) \\
\end{array}$ & $\begin{array}{c}55 \\
(52.9) \\
\end{array}$ & 0.03 \\
\hline Breakdowns $(>1)$ & $3(3.8)$ & $\begin{array}{c}13 \\
(12.5)\end{array}$ & 0.04 \\
\hline
\end{tabular}

Data are presented as number (percentage) of patients, unless stated otherwise

* $\chi 2$ Test for binary variables, analysis of variance for continuous variables

Table 4. Descriptive summary statistics across the training and control groups.

\begin{tabular}{|c|c|c|}
\hline Variable & $\begin{array}{c}\text { Breakdown } \\
\text { OR } \\
(95 \% \mathrm{CI})\end{array}$ & p-value \\
\hline \multicolumn{3}{|l|}{ Handoff Training } \\
\hline Handoff Training & $\begin{array}{l}0.29(0.08- \\
1.07)\end{array}$ & \multirow[t]{2}{*}{0.06} \\
\hline No Handoff Training & Ref & \\
\hline Charlson Score $>2$ & $\begin{array}{l}0.78(0.27- \\
2.24)\end{array}$ & 0.65 \\
\hline \multicolumn{3}{|l|}{ Patient days in the unit } \\
\hline $\begin{array}{l}\text { No. of days in the unit } \\
\text { before handoff }=0\end{array}$ & $\begin{array}{l}1.53(0.30- \\
7.78)\end{array}$ & \multirow[t]{2}{*}{0.61} \\
\hline $\begin{array}{l}\text { No. of days in the unit } \\
\text { before handoff }>0\end{array}$ & $\operatorname{Ref}$ & \\
\hline
\end{tabular}

We found that the training group was less likely to experience a breakdown in communication during handoffs (3.8\% vs. $12.5 \%$; $\mathrm{p}=0.04)$. However, after controlling for Charlson score and patient days in the unit, the communication breakdowns in both groups were similar ( $\mathrm{OR}=0.3$, 95\% CI 0.08-1.15; $\mathrm{p}=0.06$ ) (See Tables 3 and 4).

However, there were significant differences in the nature of clinical content that was discussed. Compared to the control group, residents in the training group discussed significantly more clinical content related to identifying information (5.8\% vs. $4.2 \%$; $\mathrm{p}=0.02)$, past medical history (6.6\% vs. $3.4 \%$; $\mathrm{p}<0.0001$ ), and contextual information regarding the patient $(16.2 \%$ vs. $10.7 \%$; $\mathrm{p}<0.0001)$; the training group also discussed less clinical content related to active problems $(8.8 \%$ vs. $10.9 \% ; \mathrm{p}=0.02)$ and assessment of active problems $(27.3 \%$ vs. $34.5 \%$, $\mathrm{p}<0.0001$ ).

\section{Discussion}

We found that a routine didactic handoff training during resident orientations may have had limited impact on the quality of resident communication, however there were significant differences between the groups in the nature of clinical content that was exchanged during handoffs. In this section, we discuss potential reasons for our findings and their implications to training and design of information and communication systems 
Although the lack of differences between the training and control groups after controlling for the differences was disappointing, it highlights the challenges arising from the limited empirical evidence on guidelines that define good handoff training practices. As reported elsewhere, there is limited consensus on what are "appropriate outcomes" for studying the effectiveness of handoffs $[49,51,52]$. A range of outcomes has been evaluated: completed tasks [53], medical errors in an ensuing shift [8,53], potential patient harm [54], and other self-reported outcomes such as clinician satisfaction, and perceptions of handoff effectiveness using interviews [21, 24], or surveys [55, 56].

Given the complexity of handoffs-that involve two or more clinicians, varying nature of information and communication tools in the clinical environment, interactions, and other socio-technical and contextual factors - using any one of the above-mentioned metrics may not capture the true effectiveness of handoffs. However, one constant within handoffs is the information transfer through verbal communication. Although other variables and factors may vary, measuring the quality of communication content may provide a direct measure of handoff effectiveness. Towards this end, we have focused on using breakdowns in communication as a metric for evaluating the quality of a handoff $[10,11,24]$.

It must also be mentioned that the use of communication breakdowns as an outcome measure also has potential drawbacks. There is a considerable time investment in capturing, transcribing, and coding the verbal conversations during handoffs. In addition, gathering clinical data related to the patient, such as patient demographics, comorbidities, and medications require patient chart reviews, involves further effort and time. However, more recent efforts have focused on utilizing natural language processing approaches to segment, categorize, and classify handoff conversations [4].

Another aspect that may have impacted our results is related to the nature of our training program used in this exploratory study. As highlighted earlier, the training was a one-time activity performed during the unit orientation, which closely reflects what is conducted at other residency training programs in the academic centers. Hence, one can expect to find similar patterns of results (especially in terms of communication quality) in using such training approaches. This potentially points to the need for a more focused training curriculum across the educational continuum from medical school to residency, with specific instruction and assessment tools. An approach suggested by medical education experts and the ACGME would be to conceptualize a handoff activity as an "entrustable professional activity” (EPA) [17, 18, 57]. EPAs are "activities/skills essential to the practice of medicine that educators progressively entrust learners to perform [33].” Of particular relevance is EPA \#8 that emphasizes the progressive development of handoff skills to "give or receive a patient handover to transition care responsibility." Tools are under development for medical students to observe and debrief resident handoffs as well as to measure their performance on this EPA and to provide them with feedback and determine when students have reached the entrustable level [20]. Although challenging to develop valid measures for handoff competencies [34], attempts are being made to conceptualize handoffs as an EPA [58].

For instance, the IPASS handoff bundle is a wellcited example of a pediatric residency training program which formalizes the handoff EPA model $[58,59]$. Closely aligned with the EPA model, it has implemented a scaffolded curriculum of knowledge acquisition, followed by skills practice with faculty observation and feedback of resident handoffs within the workplace-based context. Additionally given that these programs are still in its infancy and are yet to be tailored and evaluated for adult patient populations $[58,60]$, the adoption of structural changes to residency curricula to incorporate similar bundled educational approaches has been very slow [61]. Moreover, the success and sustainability of these programs depend on faculty availability [62] and the available infrastructure of the healthcare learning system [33]. For example, an evaluation of the IPASS training program demonstrated significant reductions in medical error rates in only six of the nine participating hospitals [38]. A potentially viable strategy to ensure and sustain safety in handoffs would be to incentivize physicians (e.g., by providing CME credits or clinician payment bonus) at healthcare settings for their handoff performance.

Finally, we found that there were significant differences in the nature of clinical content exchanged between the groups, with increased discussion in the training group on content related to patient identifying information, past medical history, and contextual information regarding the unit, patient family, and also the social aspects of residentresident conversation [47]. These differences, particularly related to patient and social context reflects the importance of training clinicians to pay attention to clinical content categories crucial to achieve effective patient-centered care [63]. The importance of exchanging contextual information during resident handoffs, often not found in the EHR [64], was stressed during our handoff training 
exercise as a mechanism to foster situational awareness of the unit [65], and finally to promote social interaction, a function of handoffs [11]. Handoff researchers, clinicians and medical educational experts have emphasized the different functions of handoff communication such as distributed cognition and resilience to errors. Our study points to the importance of emphasizing the functions of handoff communication and their role in patient safety and care continuity, which is lacking in current residency training programs despite the plethora of handoff skill training methods available to educators.

These findings can also inform guidelines for the development and design of handoff communication systems. In particular, our findings on the nature of clinical content shared between residents in the training group illustrates the relevance of communicating and creating information fields for recording patient identifying information, past medical history, contextual information related to the unit and patient situation, and patient active problems and their clinical assessment.

We acknowledge several limitations in our study. First, the study was conducted at a single unit in one academic medical center. Although we had a relatively large sample of patients $(n=184)$, this exploratory study was potentially underpowered to detect the differences between the two groups using communication breakdowns as the outcome of interest. However, we believe that the insights from this pilot study provide a basis for reliably establishing appropriate sample sizes for future studies on comparing handoff effectiveness. Second, the SOAP-based structure of the handoff tool used by the residents may have had an impact on the clinical content that was presented. However, this did not have an impact on our findings related to content differences between the control and training groups, given that both groups used the same tool structure. Third, we did not collect any information on the participants' prior experience with handoffs and the SOAP handoff tool. However, since all our participants were new to the unit, their prior knowledge on handoffs may not have any significant impact on the results. It is also possible that residents in the control group obtained similar educational sessions as the training intervention when they were medical students though it is possible that such knowledge and skills may have decayed. The training did not involve mechanisms for monitoring the handoffs or the residents' progress during the course of the study and we only collected data at a single time point in the study [66]. Finally, given the observational nature of this study, there is a potential for contamination, where the residents in the training group discussed the training program with their peers in the control group (although they were informally asked not to).

\section{Conclusion}

Despite national-level efforts to improve the effectiveness of resident handoffs through the development and implementation of training and educational programs [67], we are yet to witness a significant reduction in handoff errors [68]. Consequently, resident handoffs continue to be a major patient safety threat in academic healthcare settings [33, 69] and calls for formalized handoff training for residents have been unanimous. However, there is limited, if any, consensus on the strategies for training residents and medical students on effective handoff practices.

We evaluated the effects of routine handoff training on the quality of handoff communication. Although the training did not create significant differences in terms of the quality of communication, there were inherent structural differences in the nature of communication across the control and training groups. The fragmented nature of current handoff training efforts in residency programs, affects the consistency and quality of handoffs potentially leading to adverse outcomes. Sustained efforts in developing handoff training programs should ideally be incorporated into medical school curricula as EPAs that are imparted through education and hands-on exercises. The development of metrics, ideally related to the communication quality of handoffs, can also help in developing more reliable measures for evaluating handoffs.

\section{References}

[1] Nasca, T.J., S.H. Day, and E.S. Amis Jr, The new recommendations on duty hours from the ACGME Task Force. New England Journal of Medicine, 2010. 363(2): p. e(3) 1-6.

[2] Fletcher, K.E., D.A. Reed, and S. Target, Are Residency Duty Hour Rules Improving Patient Safety?

[3] Denson, J.L., et al., Increased mortality rates during resident handoff periods and the effect of ACGME duty hour regulations. The American journal of medicine, 2015. 128(9): p. 994-1000.

[4] Abraham, J., et al., Measuring Content Overlap during Handoff Communication: A MixedMethod Approach. Journal of Biomedical Informatics, In Press. 
[5] Abraham, J., et al., Comparative evaluation of the content and structure of communication using two handoff tools: implications for patient safety. Journal of critical care, 2014. 29(2): p. 311e1-e7.

[6] Abraham, J., et al. Ensuring Patient Safety in Care Transitions: An Empirical Evaluation of a Handoff Intervention Tool. in Proceedings of AMIA 2012. 2012. Chicago, IL.

[7] Abraham, J., T.G. Kannampallil, and V.L. Patel, Bridging Gaps in Handoffs: A Continuity of Care Approach. Journal of Biomedical Informatics, 2012. 45(2): p. 240-254.

[8] Singh, H., et al., Medical errors involving trainees: a study of closed malpractice claims from 5 insurers. Archives of internal medicine, 2007. 167(19): p. 2030-2036.

[9] Van Eaton, E.G., et al., Safety of using a computerized rounding and sign-out system to reduce resident duty hours. Academic medicine, 2010. 85(7): p. 1189-1195.

[10] Abraham, J., et al. Ensuring patient safety in care transitions: an empirical evaluation of a Handoff Intervention Tool. in AMIA Annual Symposium Proceedings. 2012. American Medical Informatics Association.

[11] Abraham, J., T.G. Kannampallil, and V.L. Patel, A Systematic Review of the Literature on the Evaluation of Handoff Tools: Implications for Research and Practice. Journal of American Medical Informatics Association, 2014. 21(1): p. 154-162.

[12] Johnson, J.K. and V.M. Arora, Improving clinical handovers: creating local solutions for a global problem. Quality and Safety in Health Care, 2009. 18(4): p. 244-245.

[13] Cleland, J.A., et al., There is a chain of Chinese whispers...": empirical data support the call to formally teach handover to prequalification doctors. Quality and Safety in Health care, 2009. 18(4): p. 267-271.

[14] Arora, V.M., et al., A theoretical framework and competency-based approach to improving handoffs. Quality and Safety in Health Care, 2008. 17(1): p. 11-14.

[15] Gordon, M. and R. Findley, Educational interventions to improve handover in health care: a systematic review. Medical Education, 2011. 45(11): p. 1081-1089.
[16] Wohlauer, M.V., et al., The patient handoff: $a$ comprehensive curricular blueprint for resident education to improve continuity of care. Academic Medicine, 2012. 87(4): p. 411-418.

[17] Accreditation Council for Graduate Medical Education (ACGME), Program director guide to thecommon program requirements. 2016.

[18] Accreditation Council for Graduate Medical Education (ACGME), Clinical learning environment review (CLER) program. 2016.

[19] Drachsler, H., et al., The Handover Toolbox: a knowledge exchange and training platform for improving patient care. BMJ quality \& safety, 2012. 21 (Suppl 1) p. 114-120.

[20] Colleges, A.o.A.M., The Core Entrustable Professional Activities for Entering Residency. 2016.

[21] Horwitz, L.I., et al., Consequences of inadequate sign-out for patient care. Archives of Internal Medicine, 2008. 168(16): p. 1755-1760.

[22] Liston, B.W., et al., Handoff practices in undergraduate medical education. Journal of general internal medicine, 2014. 29(5): p. 765769.

[23] Solet, D.J., et al., Lost in translation: challenges and opportunities in physician-to-physician communication during patient handoffs. Academic Medicine, 2005. 80(12): p. 1094-1099.

[24] Airan-Javia, S.L., et al., Effects of Education on Interns' Verbal and Electronic Handoff Documentation Skills. Journal of graduate medical education, 2012. 4(2): p. 209-214.

[25] Mariano, M.T., V. Brooks, and M. Digiacomo, PSYCH: A Mnemonic to Help Psychiatric Residents Decrease Patient Handoff Communication Errors. The Joint Commission Journal on Quality and Patient Safety, 2016. 42(7): p. 316-320.

[26] Chu, E.S., et al., A structured handoff program for interns. Academic Medicine, 2009. 84(3): p. 347-352.

[27] De Voge, J.M., et al., The development of a Webbased resident sign-out training program, in IEEE International Conference on Systems, Man and Cybernetics. 2009. p. 2509-2514.

[28] Horwitz, L.I., T. Moin, and M.L. Green, Development and implementation of an oral signout skills curriculum. Journal of general internal medicine, 2007. 22(10): p. 1470-1474. 
[29] Telem, D.A., et al., Integration of a formalized handoff system into the surgical curriculum: resident perspectives and early results. Archives of Surgery, 2011. 146(1): p. 89-93.

[30] Farnan, J.M., et al., Hand-off education and evaluation: piloting the observed simulated handoff experience (OSHE). Journal of general internal medicine, 2010. 25(2): p. 129-134.

[31] Filichia, L., et al., Description of web-enhanced virtual character simulation system to standardize patient handoffs. Journal of Surgical Research, 2011. 166(2): p. 176-181.

[32] Stoyanov, S., et al., Mapping and assessing clinical handover training interventions. Quality and Safety in Health Care, 2012. 21 (Suppl 1): p. 50-57.

[33] Aylward, M., J. Nixon, and S. Gladding, An entrustable professional activity (EPA) for handoffs as a model for EPA assessment development. Academic Medicine, 2014. 89(10): p. 1335-1340.

[34] ten Cate, O. and J.Q. Young, The patient handover as an entrustable professional activity: adding meaning in teaching and practice. BMJ Quality \& Safety, 2012. 21(Suppl 1): p. i9-i12.

[35] Stoyanov, S., et al., Mapping and assessing clinical handover training interventions. BMJ quality \& safety, 2012. 21(Suppl 1): p. i50-i57.

[36] Riesenberg, L.A., et al., Residents' and attending physicians' handoffs: a systematic review of the literature. Academic Medicine, 2009. 84(12): p. 1775-1787.

[37] Wohlauer, M.V., et al., The patient handoff: $a$ comprehensive curricular blueprint for resident education to improve continuity of care. Academic medicine: journal of the Association of American Medical Colleges, 2012. 87(4): p. 411.

[38] Starmer, A.J., et al., Changes in medical errors after implementation of a handoff program. New England Journal of Medicine, 2014. 371(19): p. 1803-1812.

[39] Kozij, N.K., M.K. Devlin, and B.M. Wong, Metrics for Evaluating the Quality of Handovers-Reply. JAMA internal medicine, 2015. 175(4): p. 655-655.

[40] Matt, V. and H. Matthew, The retrospective chart review: important methodological considerations. Journal of educational evaluation for health professions, 2013. 10: p. 12.

[41] Worster, A. and T. Haines, Advanced statistics: understanding medical record review (MRR) studies. Academic Emergency Medicine, 2004. 11(2): p. 187-192.

[42] Anthony, M.K. and G. Preuss, Models of care: The influence of nurse communication on patient safety. Nursing Economics, 2002. 20(5): p. 209.

[43] Friesen, M.A., S.V. White, and J.F. Byers, Handoffs: implications for nurses. 2008.

[44] Charlson, M., et al., Validation of a combined comorbidity index. Journal of clinical epidemiology, 1994. 47(11): p. 1245-1251.

[45] Charlson, M.E., et al., A new method of classifying prognostic comorbidity in longitudinal studies: development and validation. Journal of chronic diseases, 1987. 40(5): p. 373-383.

[46] Brasel, K.J., et al., Length of stay: an appropriate quality measure? Archives of Surgery, 2007. 142(5): p. 461-466.

[47] Abraham, J., et al., Characterizing the structure and content of nurse handoffs: A Sequential Conversational Analysis approach. Journal of biomedical informatics, 2016. 59: p. 76-88.

[48] Wachter, R.M., Understanding patient safety. 2012: McGraw Hill Medical New York.

[49] Johnson, J.K. and P. Barach, Patient care handovers: what will it take to ensure quality and safety during times of transition. Med J Aust, 2009. 190(11 Suppl): p. S110-12.

[50] Abraham, J., et al., Characterizing the structure and content of nurse handoffs: A Sequential Conversational Analysis approach. Journal of biomedical informatics, 2016. 59: p. 76-88.

[51] Shojania, K.G., K.E. Fletcher, and S. Saint, Graduate medical education and patient safety: a busy-and occasionally hazardousintersection. Annals of Internal Medicine, 2006. 145(8): p. 592-598.

[52] Abraham, J., T. Kannampallil, and K.F. Almoosa, Metrics for evaluating the quality of handovers. JAMA internal medicine, 2015. 175(4): p. 654-655.

[53] Starmer, A.J., et al., Changes in medical errors after implementation of a handoff program. New 
England Journal of Medicine, 2014. 37(19): p. 1803-1812.

[54] Arora, V., et al., Medication discrepancies in resident sign-outs and their potential to harm. Journal of general internal medicine, 2007. 22(12): p. 1751-1755.

[55] Stead, K., et al., Teams communicating through STEPPS. Med J Aust, 2009. 190(11 Suppl): p. S128-S132.

[56] Graham, K.L., et al., Effect of a systems intervention on the quality and safety of patient handoffs in an internal medicine residency program. Journal of general internal medicine, 2013. 28(8): p. 986-993.

[57] The Accreditation Council of Graduate Medical Education and T.A.B.o.I. Medicine, The Internal Medicine Milestone Project. 2015.

[58] Starmer, A.J., et al., Development, implementation, and dissemination of the I-PASS handoff curriculum: a multisite educational intervention to improve patient handoffs. Academic Medicine, 2014. 89(6): p. 876-884.

[59] Sawyer, T., et al., Improvements in teamwork during neonatal resuscitation after interprofessional TeamSTEPPS training. Neonatal Network, 2013. 32(1): p. 26-33.

[60] Solan, L.G., et al., Multidisciplinary Handoffs Improve Perceptions of Communication. Hospital pediatrics, 2014. 4(5): p. 311-315.

[61] Simon, T.D., et al., Quality improvement research in pediatric hospital medicine and the role of the Pediatric Research in Inpatient Settings (PRIS) network. Academic pediatrics, 2013. 13(6): p. S54-S60.

[62] Horwitz, L.I., et al., Transfers of patient care between house staff on internal medicine wards: a national survey. Archives of internal medicine, 2006. 166(11): p. 1173-1177.

[63] Baker, A., Crossing the quality chasm: A new health system for the 21st century. BMJ: British Medical Journal, 2001. 323(7322): p. 1192.

[64] Stein, D.M. and P.D. Stetson, Commentary: Time to Sign Off on Signout. Academic Medicine, 2011. 86(7): p. 804-806.

[65] Patterson, E.S. and R.L. Wears, Patient handoffs: standardized and reliable measurement tools remain elusive. The joint commission journal on quality and patient safety, 2010. 36(2): p. 52-61.
[66] Philibert, I. and S. Amis, The ACGME 2011 Duty Hour Standards: Enhancing Quality of Care. Supervision, and Resident Professional Development, 2011.

[67] Education, A.C.f.G.M., Common Program Requirements ACGME, Editor. 2011.

[68] Flemming, D. and U. Hübner, How to improve change of shift handovers and collaborative grounding and what role does the electronic patient record system play? Results of a systematic literature review. International journal of medical informatics, 2013. 82(7): p. 580-592.

[69] Vidyarthi, A.R., et al., Managing discontinuity in academic medical centers: Strategies for a safe and effective resident sign-out. Journal of Hospital Medicine, 2006. 1(4): p. 257-266. 